University of Nebraska - Lincoln

DigitalCommons@University of Nebraska - Lincoln

Uniformed Services University of the Health

Sciences

U.S. Department of Defense

2011

\title{
In vitro profiling of epigenetic modifications underlying heavy metal toxicity of tungsten-alloy and its components
}

\author{
Ranjana Verma \\ Uniformed Services University of the Health Sciences, Ranjana.Verma.CTR@usuhs.mil \\ Xiufen Xu \\ Uniformed Services University of the Health Sciences, Xiufen.Xu.CTR@usuhs.mil \\ Manoj K. Jaiswal \\ Uniformed Services University of the Health Sciences, Manoj.Jaiswal.CTR@usuhs.mil \\ Cara Olsen \\ Uniformed Services University of the Health Sciences, colsen@usuhs.mil \\ David Mears \\ Uniformed Services University of the Health Sciences, dmears@usuhs.mil \\ See next page for additional authors
}

Follow this and additional works at: https://digitalcommons.unl.edu/usuhs

Part of the Medicine and Health Sciences Commons

\begin{abstract}
Verma, Ranjana; Xu, Xiufen; Jaiswal, Manoj K.; Olsen, Cara; Mears, David; Caretti, Giuseppina; and Galdzicki, Zygmunt, "In vitro profiling of epigenetic modifications underlying heavy metal toxicity of tungsten-alloy and its components" (2011). Uniformed Services University of the Health Sciences. 89. https://digitalcommons.unl.edu/usuhs/89
\end{abstract}

This Article is brought to you for free and open access by the U.S. Department of Defense at DigitalCommons@University of Nebraska - Lincoln. It has been accepted for inclusion in Uniformed Services University of the Health Sciences by an authorized administrator of DigitalCommons@University of Nebraska Lincoln. 


\section{Authors}

Ranjana Verma, Xiufen Xu, Manoj K. Jaiswal, Cara Olsen, David Mears, Giuseppina Caretti, and Zygmunt Galdzicki 


\title{
In vitro profiling of epigenetic modifications underlying heavy metal toxicity of tungsten-alloy and its components
}

\author{
Ranjana Verma a,b ${ }^{\text {, }}$ Xiufen Xu ${ }^{\text {a }}$, Manoj K. Jaiswal ${ }^{\text {a,b }}$, Cara Olsen ${ }^{\text {c }}$, David Mears ${ }^{\text {a }}$, \\ Giuseppina Caretti ${ }^{\text {, }}$ Zygmunt Galdzicki a,b,* \\ a Anatomy, Physiology and Genetics, Uniformed Services University of the Health Sciences, Bethesda, MD 20814, USA \\ ${ }^{b}$ Center for Neuroscience and Regenerative Medicine, Uniformed Services University of the Health Sciences, Bethesda, MD 20814, USA \\ ${ }^{c}$ Department of Preventive Medicine and Biometrics, Uniformed Services University of the Health Sciences, Bethesda, MD 20814, USA \\ d Department of Biomolecular Sciences and Biotechnology, University of Milan, Italy
}

\section{A R T I C L E I N F O}

\section{Article history:}

Received 5 January 2011

Revised 29 March 2011

Accepted 4 April 2011

Available online 14 April 2011

\section{Keywords:}

Tungsten-alloy

Nickel

Cobalt

H3-histone modifications

Cytotoxicity

Epigenetics

Calcium channel blockers

Calcium chelators

2-photon calcium imaging

\begin{abstract}
A B S T R A C T
Tungsten-alloy has carcinogenic potential as demonstrated by cancer development in rats with intramuscular implanted tungsten-alloy pellets. This suggests a potential involvement of epigenetic events previously implicated as environmental triggers of cancer. Here, we tested metal induced cytotoxicity and epigenetic modifications including $\mathrm{H} 3$ acetylation, H3-Ser10 phosphorylation and H3-K4 trimethylation. We exposed human embryonic kidney (HEK293), human neuroepithelioma (SKNMC), and mouse myoblast (C2C12) cultures for 1-day and hippocampal primary neuronal cultures for 1-week to $50-200 \mu \mathrm{g} / \mathrm{ml}$ of tungsten-alloy (91\% tungsten/6\% nickel/3\% cobalt), tungsten, nickel, and cobalt. We also examined the potential role of intracellular calcium in metal mediated histone modifications by addition of calcium channel blockers/chelators to the metal solutions. Tungsten and its alloy showed cytotoxicity at concentrations $>50 \mu \mathrm{g} / \mathrm{ml}$, while we found significant toxicity with cobalt and nickel for most tested concentrations. Diverse cell-specific toxic effects were observed, with $\mathrm{C} 2 \mathrm{C} 12$ being relatively resistant to tungsten-alloy mediated toxic impact. Tungsten-alloy, but not tungsten, caused almost complete dephosphorylation of H3-Ser10 in C2C12 and hippocampal primary neuronal cultures with H3-hypoacetylation in C2C12. Dramatic H3-Ser10 dephosphorylation was found in all cobalt treated cultures with a decrease in $\mathrm{H} 3$ pan-acetylation in C2C12, SKNMC and HEK293. Trimethylation of H3-K4 was not affected. Both tungsten-alloy and cobalt mediated H3-Ser10 dephosphorylation were reversed with BAPTA-AM, highlighting the role of intracellular calcium, confirmed with 2-photon calcium imaging. In summary, our results for the first time reveal epigenetic modifications triggered by tungsten-alloy exposure in C2C12 and hippocampal primary neuronal cultures suggesting the underlying synergistic effects of tungsten, nickel and cobalt mediated by changes in intracellular calcium homeostasis and buffering.
\end{abstract}

Published by Elsevier Inc.

\section{Introduction}

Heavy metals used in industrial and household applications can pose harmful health effects. In recent years, tungsten-alloys (WA) have been used in many engineering, automotive, marine and other applications requiring high-density materials. In military operations, WA containing tungsten (W; $91 \% \mathrm{w} / \mathrm{w})$, nickel $(\mathrm{Ni} ; 6 \% \mathrm{w} / \mathrm{w})$ and cobalt $(\mathrm{Co} ; 3 \% \mathrm{w} / \mathrm{w})$ has been deployed in armor-penetrating munitions as a substitute for

\footnotetext{
* Corresponding author at: Dept. of Anatomy, Physiology and Genetics, Molecular and Cell Biology, Neuroscience Programs, USUHS, School of Medicine, 4301 Jones Bridge Rd, Bethesda, MD 20814, USA. Fax: +1 3012953566.

E-mail addresses: Ranjana.Verma.CTR@usuhs.mil (R. Verma), Xiufen.Xu.CTR@usuhs.mil (X.Xu), Manoj.Jaiswal.CTR@usuhs.mil (M.K. Jaiswal), colsen@usuhs.mil (C. Olsen), dmears@usuhs.mil (D. Mears), giuseppina.caretti@unimi.it (G. Caretti),zgaldzicki@usuhs.mil (Z. Galdzicki).
}

depleted uranium. Tungsten compounds internalized as embedded shrapnel frequently cannot be removed from brain tissue because of their location and/or small size, which may cause chronic health effects. Neurological and chronic respiratory problems in metallurgy workers, miners, and in a French soldier exposed to tungsten have been reported (Chen et al., 2005; Jordan et al., 1990; Marquet et al., 1996). Tungsten exposure via drinking water has been associated with onset of acute lymphocytic leukemia clusters (Rubin et al., 2007; Sheppard et al., 2007; Steinmaus et al., 2004). Tungsten is known to alter phosphatedependent biochemical pathways in a cell-type-dependent manner that may negatively affect downstream cellular functions (Johnson et al., 2010). A rat model with intramuscular implanted tungsten-alloy pellets has shown a carcinogenic potential for tungsten-alloy in the muscle and lungs (Kalinich et al., 2005). Tungsten-alloys also instigated neoplastic transformation of human osteoblast cells indicating its genotoxic potential (Miller et al., 2001). Subtle neurobehavioral defects were observed in rats exposed to sodium tungstate (McInturf et al., 2008). 
There have been reports that suggest heavy metals as potential causative agents for Alzheimer disease (Thompson et al., 1988). Cobalt can cause toxic health effects due to over-medication with cobaltcontaining compounds (vitamin B12), high consumption of cobalt enriched foods/drinks, or occupational exposure. In orthopedic joint implants, cobalt may be released in ionic form resulting in local cell toxicity (Tsaousi et al., 2010). Cobalt has been shown to reduce neurotransmitter concentrations in rat brain (Hasan et al., 1980), speed up ATP turnover (Hediger and Milburn, 1982), inhibit mitosis (Bearden and Cooke, 1980) and impair DNA synthesis (Sirover and Loeb, 1976).

Nickel (Ni), another major component of tungsten-alloy, is commonly used in a number of industrial and household products with a potential of producing human skin allergies, lung fibrosis, and lung cancer (Lu et al., 2005). Nickel is also employed in dental alloys, where the release of nickel ions from dental implants and fillings may induce multiple detrimental effects to the soft tissue (Schmalz and Garhammer, 2002).

The cytotoxicity and carcinogenicity of heavy metals have been well recognized (for reviews see: Beyersmann and Hartwig, 2008; Denkhaus and Salnikow, 2002; Kalinich, et al., 2005; Leonard and Lauwerys, 1990; Valko et al., 2005). However, the involved mechanisms and molecular targets have not been fully elucidated because of their complex mode of action and variable degree of impact. The confounding factors may include among others the existence of several ionic/metallic forms of the same element, different metal mixtures present in the environment, cell-type/species specificity in mechanisms of action and targeting of interconnected signaling pathways (Florea and Busselberg, 2006; Riley et al., 2005). Heavy metals can induce cell death by apoptosis and necrosis through DNA fragmentation, elevated production of reactive oxygen species (ROSs), triggering hypoxia like-effects, elevating levels of p53, activating caspases, and mitogen activated protein kinases (MAPKs) or other signaling pathways (for reviews see: Akita et al., 2007; Valko, et al., 2005; Zou et al., 2002). Heavy metals are also known to affect calcium homeostasis by blocking voltage-dependent calcium channels and inducing calcium release from intracellular calcium stores, thereby, interfering with multiple downstream signaling cascades (McNulty and Taylor, 1999; Miledi et al., 1989; Platt and Busselberg. 1994; Smith et al., 1989).

The low mutagenic and high carcinogenic activities of heavy metals suggest potential involvement of epigenetic events (histone modifications and DNA methylation) previously implicated as environmental triggers of cancer (Ziech et al., 2010). Recent studies have reported histone hypoacetylation, increased methylation/ubiquitination of histones (Costa et al., 2005; Ke et al., 2006; Li et al., 2009) and changes in the chromatin stationary structure (Ellen et al., 2009) in response to nickel and cobalt exposure. These studies also pointed to hypoxia and ROSs generation as causes of decreased acetyl-CoA, a substrate for histone acetylation due to heavy metal exposure (Costa, et al., 2005). As far as we know, there have been no published reports regarding the epigenetic effects induced by tungsten-alloy exposure.

In the present study, we have implemented in vitro models to measure the dose-dependent toxic effects of tungsten-alloy and its constituent metals including tungsten, nickel and cobalt. Considering that the metal ions can have cell-specific effects, we have used three cell-lines of human and rodent origin as well as murine hippocampal primary neuronal cultures. The use of primary hippocampal cultures was important for the evaluation of the toxic effects in neurons and to establish the neurological signature of tungsten-alloy's detrimental activity. Hippocampal primary neuronal cultures can be easily maintained for up to two weeks, facilitating the assessment of cellular toxic effects caused by long-term metal exposure in a neuronal system. We also determined the epigenetic changes that involved histone modifications in response to heavy metal exposure. It is well established that posttranslational modifications of histone proteins, for instance acetylation of histone $\mathrm{H} 3$ and its phosphorylation may affect transcription through mitogen-responsive promoters (He and Lehming, 2003). Previous studies showed that heavy metals disturb calcium homeostasis and interfere with its intracellular functions (McNulty and Taylor, 1999; Miledi, et al., 1989; Platt and Busselberg, 1994; Smith, et al., 1989). In order to better understand the interference between heavy metals and physiological calcium, calcium specific channel blockers and calcium chelators were applied during the tungsten-alloy and cobalt exposure. A series of experiments using 2-photon calcium imaging was carried out to determine intracellular calcium dynamics and physiological modulation of intracellular calcium homeostasis after exposure to tungsten-alloy. In general our results show that exposure of cells to tungsten-alloy and its components in culture conditions impacts epigenetic regulations in cell-specific manner.

\section{Materials and methods}

Chemicals. All metal solutions, including tungsten ICP/DCP (catalog \# 356697), cobalt ICP/DCP (catalog \# 356174) and nickel ICP/DCP (catalog \# 356409) as well as calcium chelators BAPTA-AM [1,2-Bis(2aminophenoxy)ethane- $\mathrm{N}, \mathrm{N}, \mathrm{N}^{\prime}, \mathrm{N}^{\prime}$-tetraacetic acid tetrakis(acetoxymethyl ester)] and EGTA [Ethylene glycol-bis(2-aminoethylether)-N, $\mathrm{N}^{\prime} \mathrm{N}^{\prime}, \mathrm{N}^{\prime}-$ tetraacetic acid] were purchased from Sigma-Aldrich (St. Louis, MO). Ltype calcium channel blockers (nimodipine and calcicludine) were purchased from Alomone Labs (Jerusalem, Israel). All other solutions were obtained from either Sigma-Aldrich (St. Louis, MO), Invitrogen (Carlsbad, CA) or Millipore (Billerica, MA).

Cell culture. C2C12 (mouse myoblast), HEK293 (human embryonic kidney) and SKNMC (human neuroepithelioma) cell lines were maintained using T75 tissue culture flasks in Dulbecco's modified Eagle's medium (DMEM) supplemented with $10 \%$ fetal bovine serum and $1 \%$ penicillin/streptomycin at $37{ }^{\circ} \mathrm{C}$ and $5 \% \mathrm{CO}_{2}$. Cells were passaged routinely after reaching $80 \%$ confluency. Hippocampal primary neuronal cultures were prepared from 3-day-old B6C3H-F1 mouse pups (P2) using a slight modification of the protocol as previously described (Best et al., 2007; Klein et al., 2001; Stoll and Galdzicki, 1996). Briefly, hippocampi were dissected, treated with $0.25 \%$ trypsin for $15 \mathrm{~min}$ at $37{ }^{\circ} \mathrm{C}$ and dissociated by trituration through the narrow bore of a fire-polished glass pipette. The single cell suspension was plated onto poly-D-lysine coated 24 well tissue culture plates $(15,000$ cells per well) or $35 \times 10 \mathrm{~mm}$ dishes $(50,000$ cells per dish) in Neurobasal ${ }^{\mathrm{TM}}$-A medium supplemented with B27, $10 \%$ fetal bovine serum, $5 \%$ horse serum, $1 \%$ glutamine and $1 \%$ penicillin/streptomycin at $37{ }^{\circ} \mathrm{C}$ and $5 \% \mathrm{CO}_{2}$. After one hour, the plating media were replaced with feeding media i.e. Neurobasal ${ }^{\mathrm{TM}}-\mathrm{A}$ medium supplemented with B27 and 1\% glutamine.

Metal exposure. In vitro cultures were exposed to nickel, cobalt, tungsten, tungsten-alloy $(91 \% \mathrm{~W}, 6 \% \mathrm{Ni}, 3 \% \mathrm{Co})$ as well as the same amount of nickel $(\mathrm{NiA})$ and cobalt $(\mathrm{CoA})$ that is used in the preparation of tungsten-alloy solutions. Metal concentrations used in this study in units of ' $\mu \mathrm{g} / \mathrm{ml}$ ' and corresponding ' $\mu \mathrm{M}$ ' values are presented in Supplementary Table 1 . Based on the previous literature, we selected three different metal concentrations, including $50 \mu \mathrm{g} / \mathrm{ml}, 100 \mu \mathrm{g} / \mathrm{ml}$ and $200 \mu \mathrm{g} / \mathrm{ml}$ for cytotoxicity assays (Kane et al., 2009; Peuster et al., 2003). For analyzing alterations in histone modifications, all four cultures were treated with the same metal solutions at a concentration of $50 \mu \mathrm{g} / \mathrm{ml}$ and $1000 \mu \mathrm{M}$ (nearly equivalent to $58.7 \mu \mathrm{g} / \mathrm{ml}$ of nickel, $58.9 \mu \mathrm{g} / \mathrm{ml}$ of cobalt and $183.9 \mu \mathrm{g} / \mathrm{ml}$ of tungsten and tungsten-alloy). All three cell lines were exposed to metal solutions for $24 \mathrm{~h}$ after reaching $80 \%$ confluency. Primary hippocampal cultures were exposed for 1-week to different concentrations of metal solutions on the 5th day of culture, when neurons reach their physiological maturation status (Best, et al., 2007). We selected one week exposure for differentiated neuronal cultures to model long-term exposure effects of tungsten and its alloy. Metal 
solutions in the respective media were prepared prior to use. The $\mathrm{pH}$ of all metal solutions used for the above experiments was $~ 7.4$.

Exposure to calcium channel blockers and calcium chelators. C2C12 cells (with L-type calcium channels) were exposed to $1000 \mu \mathrm{M}$ of cobalt or tungsten-alloy (nearly equivalent to $58.9 \mu \mathrm{g} / \mathrm{ml}$ of cobalt and $183.9 \mu \mathrm{g} / \mathrm{ml}$ of tungsten-alloy) in combination with either of the two L-type calcium channel blockers including nimodipine $(2 \mu \mathrm{M})$ or calcicludine $(0.01 \mu \mathrm{M})$ for $24 \mathrm{~h}$. Similarly, another set of C2C12 cells was treated with $1000 \mu \mathrm{M}$ of cobalt or tungsten-alloy along with $50 \mu \mathrm{M}$ of BAPTA-AM (intracellular calcium chelator) or $3 \mathrm{mM}$ of EGTA (extracellular calcium chelator) or both BAPTA-AM as well as EGTA together for $24 \mathrm{~h}$. While BAPTA-AM was added $2 \mathrm{~h}$ prior to metal exposure, EGTA as well as nimodipine and calcicludine were added at the same time as the metal exposure. We also exposed control C2C12 cultures to similar concentrations of calcium channel blockers and chelators as mentioned above without any metal treatment.

2-photon microscopy and calcium imaging. Metal-induced changes in baseline intracellular calcium concentration $\left(\left[\mathrm{Ca}^{2+}\right]_{\mathrm{i}}\right)$ and cellular activity over time were measured in control $\mathrm{C} 2 \mathrm{C} 12$ cells as well as cultures exposed for $24 \mathrm{~h}$ to tungsten-alloy or tungsten-alloy plus BAPTA-AM. The calcium-sensitive fluorescent dye was introduced into C2C12 cells by adding $2 \mu \mathrm{M}$ of cell membrane-permeable Fluo-4/ AM (Invitrogen) into the media of the culture plates followed by incubation at $37^{\circ} \mathrm{C}, 5 \% \mathrm{CO}_{2}$ for $40 \mathrm{~min}$. Cells were rinsed with DMEM and incubated for $20 \mathrm{~min}$ at $37^{\circ} \mathrm{C}$ to allow for complete deesterification (for details see Jaiswal and Keller, 2009). Changes in $\left[\mathrm{Ca}^{2+}\right]_{\mathrm{i}}$ were measured using a Zeiss LSM 7 MP system (Carl Zeiss Microlmaging, Germany).

In brief, experiments were performed as previously described (Bergmann and Keller, 2004; Jaiswal and Keller, 2009) using a Zeiss LSM 7 MP system, consisting of an Axio Examiner.Z1 microscope (Carl Zeiss MicroImaging, Germany), Ti:sapphire Chameleon Vision, 2-photon mode-locked laser system operated at $800 \mathrm{~nm}$ (680 nm$1080 \mathrm{~nm}$ tuning range, $80 \mathrm{MHz} ; 3.3 \mathrm{~W}$ peak power , Coherent, Inc., Auburn, CA) and controlled by Zen 2009 software (Zeiss, Germany). The system was equipped with a X-Cite 120 lamp for reflected light illumination and water immersion objectives (10× achroplan and $20 \times$ plan-apochromat, $40 \times$ plan-apochromat, $0.30,1.0$ and $0.8 \mathrm{NA}$ respectively, Zeiss; Germany). Laser excitation and fluorescence emission were separated by a $690 \mathrm{~nm}$ long pass and the emitted fluorescence was detected through 525/50 band pass filter (Chroma Technology, Rockingham, VT) with non-descanned detectors.

In time series experiments, dynamic intracellular calcium changes in defined regions of interest (ROIs) were monitored using Zeiss Zen 2009 software equipped with physiology module. The image acquisition rate was $\sim 2.5 \mathrm{~Hz}$. Further analysis was performed off-line with the Zeiss Zen 2009 (Carl Zeiss MicroImaging, Germany), OriginPro 8.5 software (OriginLab Corporation, Northampton, MA, USA), version 8.1, IGOR software (Wavemetrics, Lake Oswego, OR, USA) and Image J. Background fluorescence was subtracted from the recorded values. The measured fluorescence intensity for RIOs was used to calculate changes in baseline calcium and cellular activity, which was represented as $\Delta \mathrm{F}$ / $\mathrm{F}_{0}=\left(\mathrm{F}-\mathrm{F}_{0}\right) / \mathrm{F}_{0}$, where $\mathrm{F}_{0}$ is the fluorescence at the beginning of recordings and $\mathrm{F}$ is the fluorescence intensity over time. The measured fluorescence signal is the function of both calcium concentration and the concentration of Fluo-4/AM, and we assume that the latter did not fluctuate during the $5 \mathrm{~min}$ recording period.

Toxicity assays. Cell viability was analyzed using the multiple endpoint IN CYTOTOX test kits from Xenometrix (Allschwil, Switzerland) that employ NR and XTT assays to evaluate cellular toxicity in the same sample (Hopp et al., 2003; Johnston et al., 1993; Kane, et al., 2009; Peuster, et al., 2003). The use of two different toxicity assays on the same culture plate increases the relevance of correlation among different tests, enhances the chance of detecting cytotoxic effects, reduces the overall handling time and the amount of test compounds needed and may also suggest mechanisms of toxicity. The NR assay involves a neutral red weak cationic dye that accumulates intracellularly in lysosomes and binds to anionic sites of the lysosomal matrix of viable cells. The XTT assay comprises a yellow tetrazolium salt that is cleaved to soluble orange formazan by the succinate dehydrogenase system present in the mitochondrial respiratory chain of viable cells. All cytotoxicity assays were performed with cells plated in 24 well tissue culture plates following the manufacturer's instructions. The absorbance of the final reaction products was determined using Fluostar Optima microplate spectrophotometer from BMG Labtech (Offenburg, Germany).

Clonogenic assay. C2C12 cultures treated with $1000 \mu \mathrm{M}$ tungstenalloy for $24 \mathrm{~h}$ as well as control cells were trypsinized and re-plated in triplicates in $100 \mathrm{~mm}$ Petri dish at a density of 2000 cells per dish (using the same plating media as mentioned above). After being incubated for two weeks, colonies were washed with PBS, fixed with methanol and stained with $0.5 \%$ crystal violet in $25 \%$ methanol. The plates were rinsed three times with water and air-dried, and then counted.

Histone extraction. Histones were isolated from the same metal exposed cultures as mentioned above at concentrations of $50 \mu \mathrm{g} / \mathrm{ml}$ and $1000 \mu \mathrm{M}$ (nearly equivalent to $58.7 \mu \mathrm{g} / \mathrm{ml}$ of nickel, $58.9 \mu \mathrm{g} / \mathrm{ml}$ of cobalt and $183.9 \mu \mathrm{g} / \mathrm{ml}$ of tungsten and tungsten-alloy) and C2C12 cultures treated with $1000 \mu \mathrm{M}$ of cobalt or tungsten-alloy in combination with either calcium blockers or calcium chelators using a modified acid extraction protocol (Shechter et al., 2007). Briefly, the cells were scraped and pelleted by centrifugation at $1500 \mathrm{rpm}$ for 10 min. The cells were washed with 10-15 volumes of PBS (with $5 \mathrm{mM}$ sodium butyrate) and then suspended in 5-10 volumes of lysis buffer $\left(10 \mathrm{mM}\right.$ HEPES - $\mathrm{pH} 7.9,1.5 \mathrm{mM} \mathrm{MgCl}_{2}, 10 \mathrm{mM} \mathrm{KCl}$ with freshly added $5 \mathrm{mM}$ sodium butyrate, $0.5 \mathrm{mM}$ DTT, $1.5 \mathrm{mM}$ PMSF, (1:100) phosphatase inhibitors cocktail I \& II (Sigma) and a tablet of complete protease inhibitor (Roche Diagnostics Corporation, Indianapolis, IN) per $10 \mathrm{ml}$ of lysis buffer). The cells in lysis buffer were incubated on a rotator at $4{ }^{\circ} \mathrm{C}$ for $30 \mathrm{~min}$ and centrifuged at $2000 \mathrm{rpm}$ for $10 \mathrm{~min}$ at $4{ }^{\circ} \mathrm{C}$. The cell pellet was washed again with half the volume of lysis buffer. The pellet was resuspended in $200 \mu \mathrm{l}-500 \mu \mathrm{l}$ of $0.2 \mathrm{~N} \mathrm{HCl}$ depending upon the pellet size, incubated on rotator at $4{ }^{\circ} \mathrm{C}$ for $1 \mathrm{~h}$ and centrifuged at $13,000 \mathrm{rpm}$ for $20 \mathrm{~min}$ at $4{ }^{\circ} \mathrm{C}$. The supernatant containing histones was transferred to fresh tube. The histone concentration was determined using $\mathrm{BCA}^{\mathrm{TM}}$ protein assay (Thermo Scientific, Hudson, NH) and a Fluostar Optima microplate spectrophotometer from BMG Labtech (Offenburg, Germany).

Western blot. 10-20\% Novex ${ }^{\circledR}$ Tricine SDS gels (Invitrogen) with resolution of $2 \mathrm{kDa}$ differences were utilized to separate purified histones following the manufacturer's instructions. The histones were transferred from the tricine gels to the polyvinylidene difluoride PVDF membranes (Pall Corporation, Ann Arbor, MI) and hybridized with either anti-acetyl-H3 (catalog \# 06-599, Millipore), antiphospho-H3-Ser10 (catalog \# 04-817, Millipore) or anti-trimethylH3-Lys4 (catalog \# 39159, Active Motif) primary antibodies. After appropriate washing procedures, the membranes were incubated with goat anti-rabbit secondary antibody (catalog \# 170-6515, BioRad). The Western blot signals were detected using Fujifilm LAS3000 Imager (Fujifilm, Stamford, CT) within the linear range. Each of these blots was then washed and hybridized with total anti-H2A antibodies (catalog \#07-146, Millipore) so as to normalize for the gel loading variation.

Statistical analysis. All cytotoxicity assays were performed two to six times in triplicate as indicated in the figure legends. The data were analyzed using one-way analysis of variance (ANOVA), with Dunnett's method as the post-hoc test to identify statistically significant dosedependent cytotoxic effects of metal exposed cell cultures as compared with controls. For quantitative analysis of Western blots, optical intensity of bands in the linear range was evaluated with a 
MultiGauge v3.0 software (Fujifilm, Stamford, CT) and each blot was repeated three times. The intensity data for each Western blot band was divided by its respective total $\mathrm{H} 2 \mathrm{~A}$ intensity (from same blot) to normalize for gel loading variation. Data was analyzed on a $\log (10)$ scale to achieve normality and equal variances among groups. We implemented one-way ANOVA with Dunnett's method as the posthoc test to identify statistical significant differences of histone modifications induced in response of exposure to heavy metals alone or in combination with calcium channel blockers/chelators in comparison with controls. Standard T-tests were employed to compare differences in mean baseline calcium in tungsten-alloy or tungsten-alloy plus BAPTA-AM treated cultures as compared to control cells. The level of significance was assigned at $\mathrm{p}<0.05$. Results are presented as Mean \pm SEM.

\section{Results}

\section{Dose-dependent toxic effects in response to metal exposure}

The toxic effects of tungsten-alloy and its constituent metals including tungsten, nickel and cobalt were tested in human embryonic kidney (HEK293), human neuroepithelioma (SKNMC), murine myoblast (C2C12) and murine postnatal hippocampal primary neuronal culture systems. We implemented three different concentrations comprising $50 \mu \mathrm{g} / \mathrm{ml}, 100 \mu \mathrm{g} / \mathrm{ml}$ and $200 \mu \mathrm{g} / \mathrm{ml}$ of metal solutions to measure the dose-dependent toxic effects. We further employed two different cytotoxicity assays (XTT and NR) on the same culture plates to increase the reliability of the results and to discriminate the effects of metals on specific cell organelles.

Tungsten and its alloy showed significant dose-dependent toxic effects at metal concentrations of $100 \mu \mathrm{g} / \mathrm{ml}$ and $200 \mu \mathrm{g} / \mathrm{ml}$ but no toxicity was observed at $50 \mu \mathrm{g} / \mathrm{ml}$. Interestingly, exposure to tungsten-alloy but not tungsten (at $100 \mu \mathrm{g} / \mathrm{ml}$ ) produced a significant decrease in cell viability for HEK293, indicating the enhanced cytotoxicity possibly induced by synergistic effects of tungsten along with nickel and cobalt (Fig. 1). The toxic effects detected with both NR and XTT assays might imply the involvement of lysosomal and mitochondrial damage as the potential underlying mechanisms for metal-induced cytotoxicity. Moreover, the tungsten-alloy toxicity observed at $100 \mu \mathrm{g} / \mathrm{ml}$ with only NR and not XTT suggests that lysosomal damage may be first in the sequence of events followed by mitochondrial defects eventually leading to cell death. Also as shown in Fig. 1, only cobalt consistently showed significant robust toxicity at all three concentrations ( $50 \mu \mathrm{g} / \mathrm{ml}, 100 \mu \mathrm{g} / \mathrm{ml}$ and $200 \mu \mathrm{g} / \mathrm{ml}$ ) tested in four diverse cell culture systems. Similar to cobalt, nickel also induced a significant reduction of cell viability with all concentrations and cultures except for $50 \mu \mathrm{g} / \mathrm{ml}$ in the $\mathrm{C} 2 \mathrm{C} 12$ cell line (Fig. 1). For concentrations of nickel ( $\mathrm{NiA}$ ) and cobalt ( $\mathrm{CoA}$ ) present in the tungstenalloy, reduced toxicity or no-toxicity was evident. Noticeable toxicity of small doses of either nickel or cobalt in hippocampal primary neuronal cultures could be explained by the higher sensitivity of hippocampal neuronal cultures toward these metals or the longer time of exposure (seven days as opposed to $24 \mathrm{~h}$ ). Clonogenic assay revealed that the number of colonies formed in the tungsten-alloy
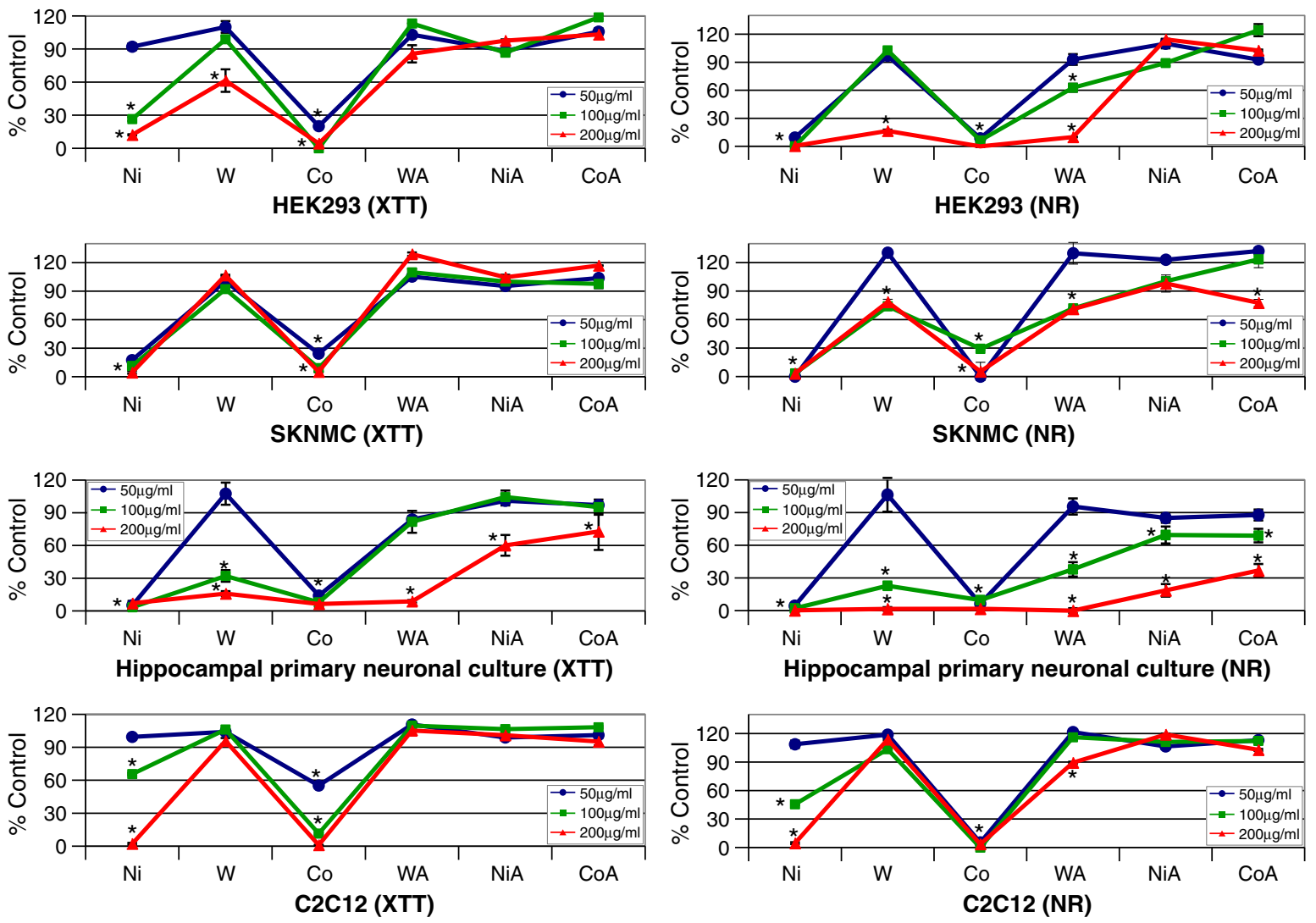

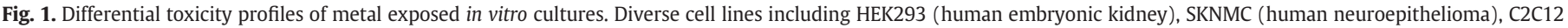

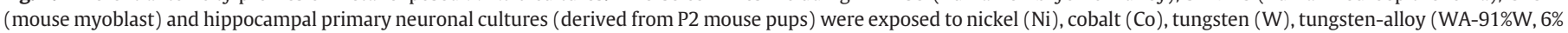

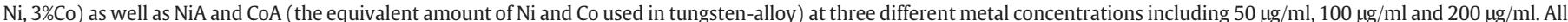

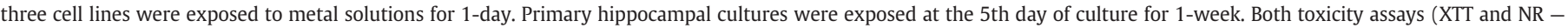

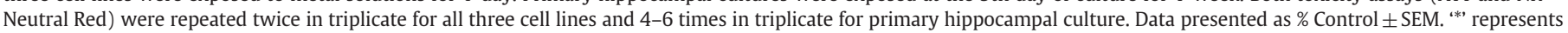
$\mathrm{p}<0.05$ for Dunnetts test following one-way ANOVA. 
treated plates was similar to control $\mathrm{C} 2 \mathrm{C} 12$ culture plates, reflecting the outcome of NR and XTT assays (Mean \% Control \pm SEM $=156 \pm 31$ ).

\section{Alterations in histone modifications induced by heavy metal exposure}

It is known that exposure to metals causes changes in gene expression and that chromatin modifications, histone $\mathrm{H} 3$ in particular play an important role in the cellular response to toxic agents (Clayton and Mahadevan, 2003; Johnson and Barton, 2007; Moggs and Orphanides, 2004). In the present study, metal-treated cell cultures were examined for alterations in three different histone modifications including trimethyl-H3-Lys4, acetyl-H3 and phospho$\mathrm{H} 3-$ Ser10 in response to metal exposure. Histone $\mathrm{H} 3$ is one of the main histone proteins that forms the nucleosome core and is highly post-translationally modified by covalent attachment of methyl or acetyl groups to lysine/arginine and phosphorylation of serine/ threonine in its $\mathrm{N}$-terminal tail. Histone acetylation of lysine residues in the H3 $\mathrm{N}$-terminal tail as well as methylation of lysine- 4 or lysine79 has been associated with transcriptional activation of genes (Annunziato and Hansen, 2000; Santos-Rosa et al., 2002). On the contrary, histone H3-Ser10 phosphorylation has been linked to very divergent cellular processes such as chromosome condensation and segregation, modulation of transcriptional activity of specific genes in response to stress/mitogens, mediation of transcription elongation via crosstalk with histone H4K16 acetylation, gene silencing, apoptosis and DNA repair (Cerutti and Casas-Mollano, 2009; PerezCadahia et al., 2009; Zippo et al., 2009). These contrasting roles of H3-Ser10 phosphorylation linked to chromosome condensation and transcriptional activation could be reconciled by the yet to be proven hypothesis that $\mathrm{H} 3$ phosphorylation actually opens up the chromatin during mitosis and gives access to nuclear factors that promote chromosome condensation. It is also possible that the final outcome of $\mathrm{H} 3$ phosphorylation is dependent upon the combinations of other histone marks present in its vicinity (Cheung et al., 2000; Santos-Rosa, et al., 2002).

The results of Western blot analysis of histones isolated from HEK293, SKNMC, C2C12 and hippocampal primary neuronal cultures showed no detectable changes in the level of trimethyl-H3-Lys4 in any of the cell cultures following metal exposure (Figs. 2A-D). This outcome suggests absence of any massive alteration in transcriptional activation of genes. Exposure to tungsten-alloy $(1000 \mu \mathrm{M} / \sim 183.9 \mu \mathrm{g} /$ $\mathrm{ml}$ ) but not tungsten itself evoked a significant reduction in phosphorylation of H3-Ser10 in hippocampal primary neuronal cultures (Fig. 2C) and C2C12 (Fig. 2D) cells, implying the potential synergistic toxic effects of tungsten with nickel and cobalt that are part of tungsten-alloy. As compared to control cells, significant reduction in the phosphorylation levels of H3-Ser10 was observed in all four cultures (Figs. 2A-D) treated with cobalt $(50 \mu \mathrm{g} / \mathrm{ml}$ or $1000 \mu \mathrm{M} / \sim 58.9 \mu \mathrm{g} / \mathrm{ml}$ ) and for cobalt concentration (CoA) present in $\sim 1000 \mu \mathrm{M} / 183.9 \mu \mathrm{g} / \mathrm{ml}$ of tungsten-alloy in C2C12 cells (Fig. 2D). Also, modest dephosphorylation of $\mathrm{H} 3$-Ser10 was observed in response to tungsten $(1000 \mu \mathrm{M} / \sim 183.9 \mu \mathrm{g} / \mathrm{ml})$ in HEK293 (Fig. 2A).

C2C12 cells also showed reduced acetylation levels (Fig. 2D) following exposure to tungsten-alloy $(\sim 1000 \mu \mathrm{M} / 183.9 \mu \mathrm{g} / \mathrm{ml})$. Furthermore, reduction in the acetylation levels of $\mathrm{H} 3$ was also observed in HEK293 (Fig. 2A), SKNMC (Fig. 2B) and C2C12 (Fig. 2D) in response to cobalt $(50 \mu \mathrm{g} / \mathrm{ml}$ or $1000 \mu \mathrm{M} / \sim 58.9 \mu \mathrm{g} / \mathrm{ml})$ exposure. No other statistically significant changes in any of the histone modifications were detected for the remaining concentrations of metal exposures used in this study.

Effects of L-type calcium channel blockers and calcium chelators on the reversal of histone modifications induced by metal exposure

To better understand the potential role of heavy metal-induced disruption of calcium homeostasis in the underlying mechanisms behind the metal-mediated epigenetic modifications, we changed the intracellular and extracellular calcium levels and determined histone H3-acetylation and H3-Ser10 phosphorylation following metal exposure in $\mathrm{C} 2 \mathrm{C} 12$ cells. Heavy metals are known to affect calcium homeostasis and dynamics by blocking voltage-dependent calcium channels and inducing calcium release from intracellular calcium stores, thereby influencing downstream signaling cascades associated with cell growth, differentiation and apoptosis (Valko, et al., 2005). It has also been previously reported that certain calcium channel blockers like nimodipine, nifedipine, verapamil etc. are capable of reducing metal uptake to a certain extent and could thus reduce metal-mediated cytotoxicity (Hinkle et al., 1987; M'BembaMeka et al., 2005). To test the possibility of reversal of metal-induced epigenetic modifications by changing calcium homeostasis, we exposed $\mathrm{C} 2 \mathrm{C} 12$ cells (that express L-type calcium channels) to $1000 \mu \mathrm{M}$ of tungsten-alloy or cobalt along with L-type calcium channel blockers (nimodipine $-2 \mu \mathrm{M}$ or calcicludine $-0.01 \mu \mathrm{M}$ ), intracellular calcium chelator (BAPTA-AM $-50 \mu \mathrm{M}$ ), extracellular calcium chelator (EGTA $-3 \mathrm{mM}$ ) and a combination of BAPTA-AM with EGTA.

After co-treatment with calcium channel blockers and metals, we did not detect any significant alteration in tungsten-alloy or cobalt mediated hypoacetylation of histone $\mathrm{H} 3$ or reduced phosphorylation levels of H3-Ser10 in C2C12 cells (Fig. 3A). Moreover, acetylation of histone $\mathrm{H} 3$ and phosphorylation of H3-Ser10 did not change after exposure of control C2C12 cells to calcium channel blockers (Fig. 3C). Similarly, treatment with calcium chelators (BAPTA-AM, EGTA, and combined BAPTA and EGTA) did not significantly impact the H3 hypoacetylation induced by either tungsten-alloy or cobalt (Fig. 3B). However treatment with BAPTA-AM as well as BAPTA-AM and EGTA together restored $\mathrm{H} 3$-Ser10 phosphorylation levels attenuated by tungsten-alloy or cobalt exposure (Fig. 3B) whereas treatment with only EGTA was ineffective in the restoration.

Based on these observations, we concluded that the decrease in histone H3-Ser10 phosphorylation levels caused by exposure to tungsten-alloy or cobalt might be the downstream effect of increased intracellular calcium or a change in intracellular calcium dynamics triggered by metal treatment, at least in $\mathrm{C} 2 \mathrm{C} 12$ cells. In fact, control C2C12 cultures treated with BAPTA-AM, EGTA or combined BAPTA-AM and EGTA revealed H3 hypoacetylation (Fig. 3C) to a similar degree as observed in tungsten-alloy or cobalt treated C2C12 cells. Also, significant reduction in the phosphorylation levels of H3-Ser10, to the same level as in tungsten-alloy or cobalt treated C2C12 cells, was observed with control C2C12 cultures exposed to EGTA (Fig. 3C). However, control cultures treated with BAPTA-AM or combined BAPTA-AM and EGTA did not show H3-Ser10 dephosphorylation because BAPTA-AM appears to chelate the intracellular calcium (see Fig. 4), hence no calcium was released from the intracellular stores even after EGTA disturbed the cellular calcium homeostasis.

Moreover, the intracellular calcium measurement using 2-photon imaging showed that the baseline intracellular calcium concentration was elevated in $\mathrm{C} 2 \mathrm{C} 12$ cells after exposure to tungsten-alloy and was significantly reduced by combined exposure to tungsten-alloy and BAPTA-AM (Fig. 4). Specifically, 1-day exposure to $1000 \mu \mathrm{M}$ of tungsten-alloy increased baseline calcium by $\sim 15 \%$, whereas 1-day exposure to $1000 \mu \mathrm{M}$ of tungsten-alloy plus $50 \mu \mathrm{M}$ of BAPTA-AM reduced baseline calcium by $\sim 60 \%$ (Figs. $4 \mathrm{~B}$ and $4 \mathrm{D}$ ). However the most dramatic effect triggered by 1-day exposure to tungsten-alloy was alteration of intracellular calcium dynamics (Fig. 4C), consisting of an increase in the percentage of active cells (cells that exhibit more than 25\% change in baseline calcium during $5 \mathrm{~min}$ of recording period). Exposure to tungsten-alloy increased the percentage of active cells from $\sim 17 \%$ to $57 \%$ (3-fold increase; Fig. 4E). These results suggest strong correlation between intracellular calcium dynamics and H3Ser10 phosphorylation. 
A

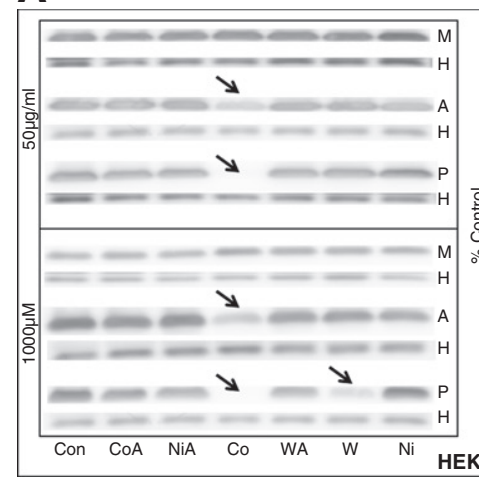

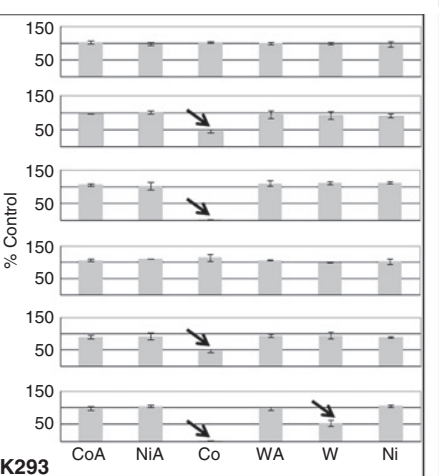

C

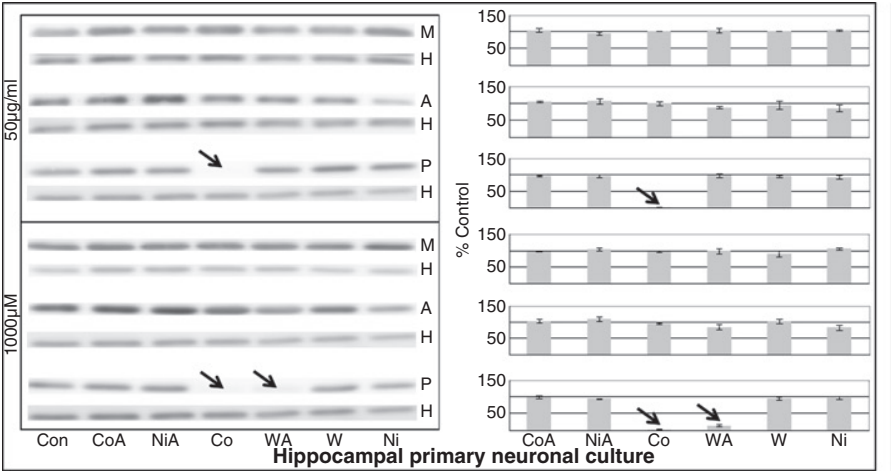

B

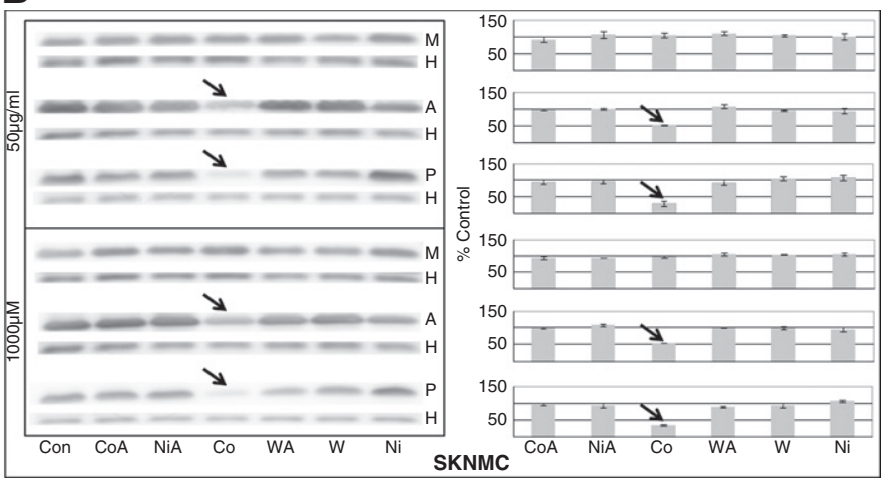

D

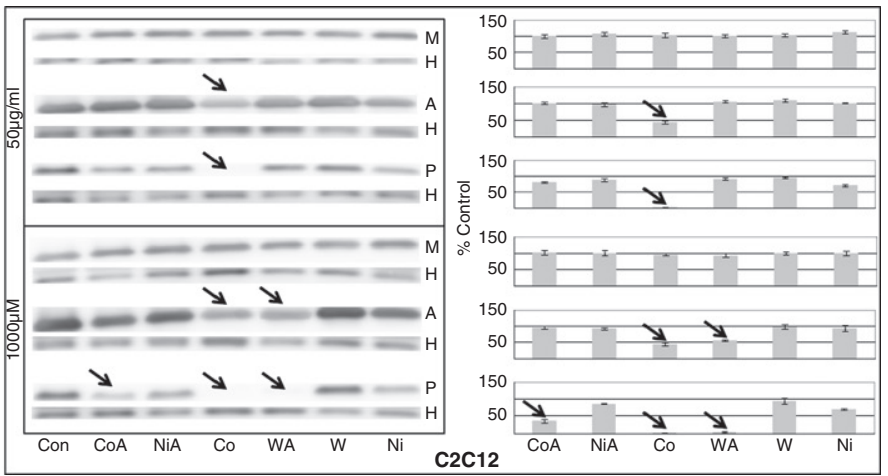

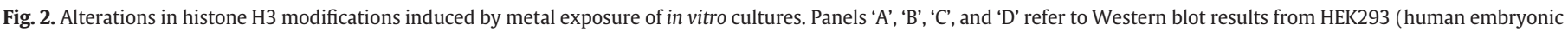

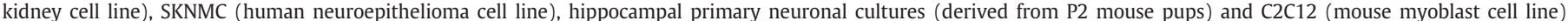

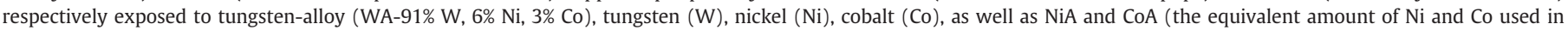

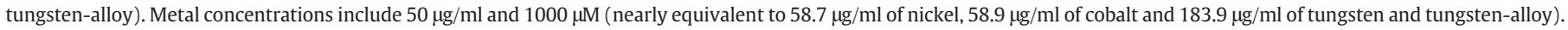

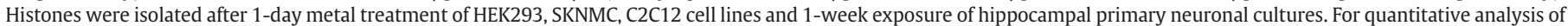

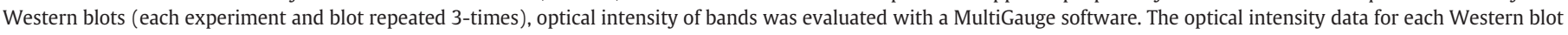

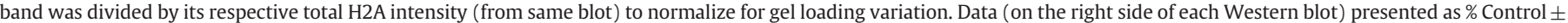

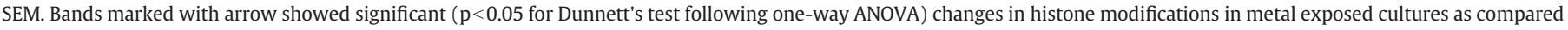
to controls (Con). 'A': acetyl-H3, 'H': total H2A, 'P': phospho-H3-Ser10, 'M': trimethyl-H3-Lys4 antibodies.

\section{Discussion}

Extensive use of heavy metals including tungsten-alloys and its constituent metals can cause harmful health effects (Kalinich, et al., 2005; Lagarde and Leroy, 2002). The employment of tungsten-alloys in military ammunition has produced a new route of long-term metal exposures as embedded shrapnels, which can be difficult to remove because of their location and/or small size (van der Voet et al., 2007). This long-term exposure could increase the risk of cancer development in injured individuals. Moreover, leakage of metal solutions to drinking water and soil because of some environmental contaminants may also increase metal exposure in the general population (Clausen and Korte, 2009; Thomas et al., 2009).

To examine dose-dependent cytotoxicity of tungsten-alloy metals, we implemented four diverse cell cultures, two derived from mice (C2C12 - mouse myoblast and hippocampal primary neuronal culture) and two cultures originated from human tissues (HEK293 - human embryonic kidney and SKNMC - human neuroepithelioma). The exposure to tungsten-alloy and tungsten showed dose-dependent toxic effects for concentration levels higher than $50 \mu \mathrm{g} / \mathrm{ml}$ (Fig. 1), while cobalt and nickel significantly affected the cell viability in almost all cell cultures at even the lowest concentration tested $(50 \mu \mathrm{g} / \mathrm{ml})$. Our observations are similar to the previous report that found tungsten toxicity at concentrations greater than $50 \mu \mathrm{g} / \mathrm{ml}$ in human pulmonary arterial endothelial, smooth muscle and human dermal fibroblasts (Peuster, et al., 2003). Furthermore, the resistance of C2C12 toward the tungsten and tungsten-alloy mediated cytotoxicity correlates with the results from earlier studies that showed very modest $(\sim 10 \%)$ toxic effects in C2C12 cultures exposed to high concentrations $(1000 \mu \mathrm{g} / \mathrm{ml})$ of tungsten-alloy (Kane, et al., 2009). The diverse toxic effects observed by the same metal concentrations observed here might be related to variable metal sensitivities of these cell cultures possibly caused by cellspecific metal uptake mechanisms or metal binding storage proteins such as thionein and other metal binding chaperones (Linder and Hazegh-Azam, 1996).

Tungsten-alloy metals exhibit significant carcinogenic effects as shown by recent studies with intramuscularly implanted tungstenalloy pellets in rats (Kalinich, et al., 2005). These carcinogenic effects can be caused by epigenetic events (histone modifications) implicated as environmental triggers of cancer (Ziech, et al., 2010). We therefore attempted to identify alterations in histone $\mathrm{H} 3$ modifications including trimethyl-H3-Lys4, acetyl-H3 and phospho-H3-Ser10 that may underlie the pathological mechanisms of heavy metal exposure. We did not observe any detectable changes in the methylation status of trimethyl-H3-Lys4. Tungsten-alloy but not tungsten alone caused significant dephosphorylation $\mathrm{H} 3-\mathrm{Ser} 10$ in $\mathrm{C} 2 \mathrm{C} 12$ (Fig. 2D) and hippocampal primary neuronal culture (Fig. 2C) as well as attenuated level of H3-acetylation in C2C12 cultures (Fig. 2D). We also found a significant reduction in phosphorylation levels of H3-Ser10 in all cultures treated with cobalt (Figs. 2A-D). Furthermore, a decrease in acetylation levels of histone H3 was found in cobalt treated HEK293, SKNMC and C2C12 cultures (Figs. 2A, 2B, and 2D). The cobalt-induced histone modifications could be the result of downstream toxic effects of cobalt, however, the failure to observe any histone modifications in 
A
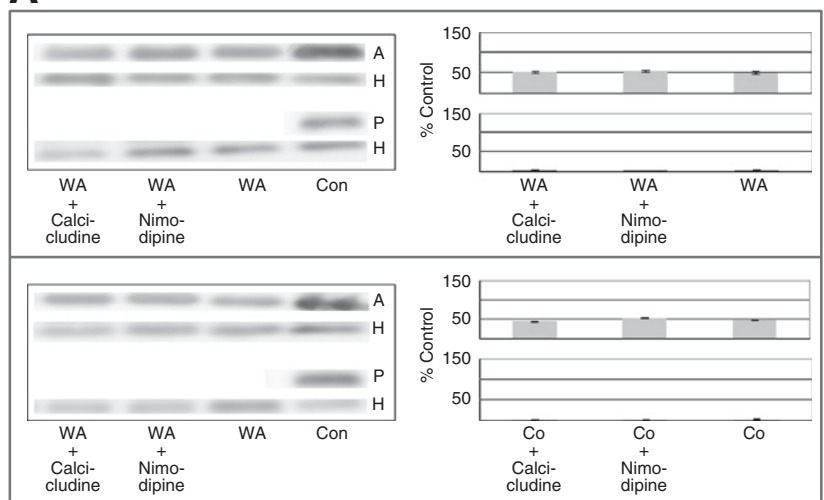

C
B

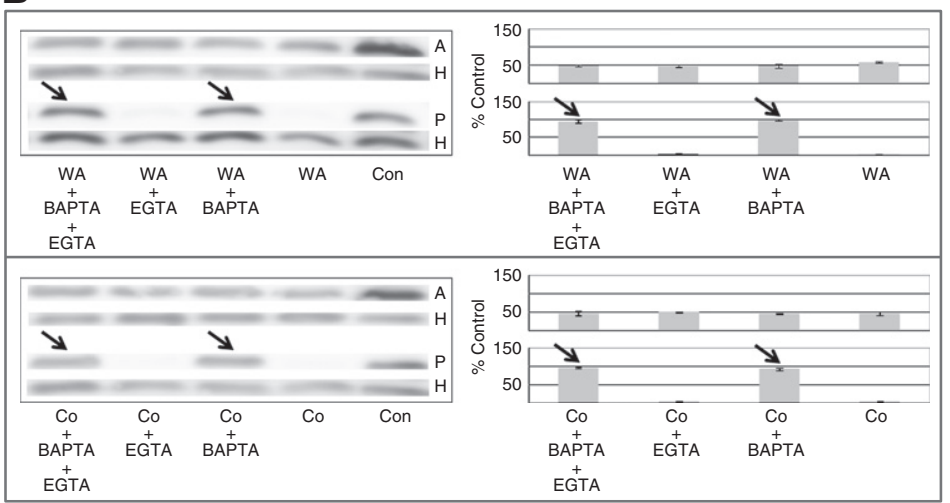

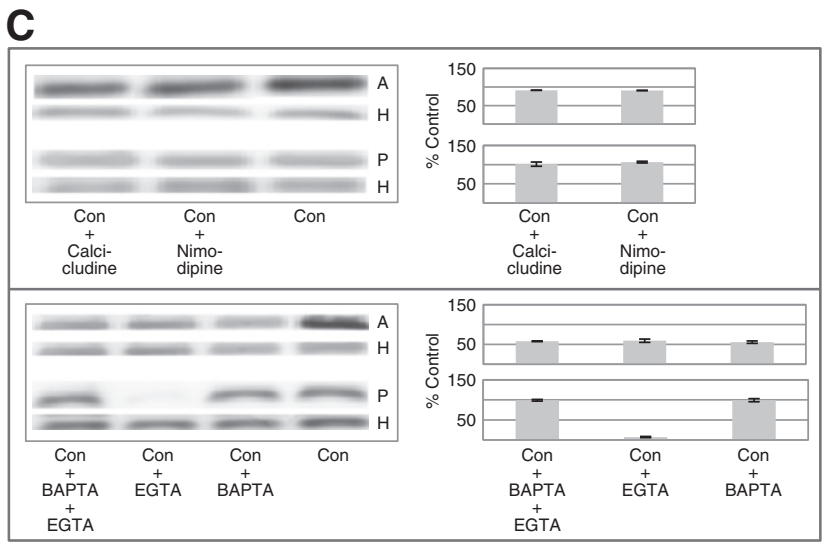

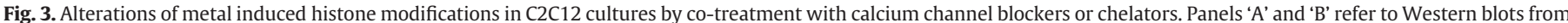

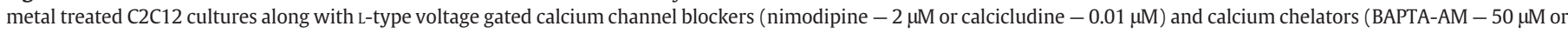

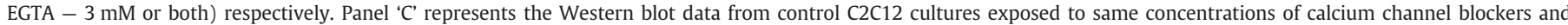

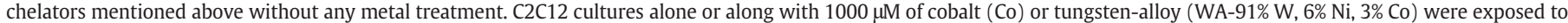

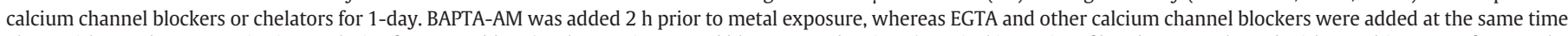

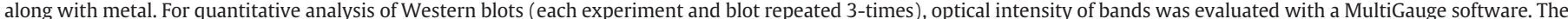

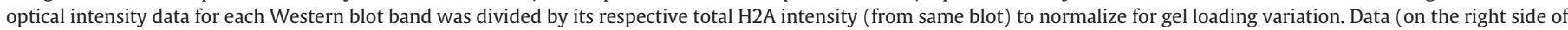

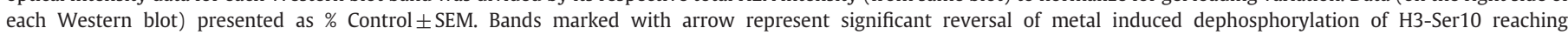
phosphorylation levels close to the one observed for controls (Con). 'A': acetyl-H3, 'H': total H2A, 'P': phospho-H3-Ser10 antibodies.

response to an equally toxic dose of nickel possibly suggests and supports the crucial role of cobalt in mediating epigenetic changes apart from cell viability defects. Moreover, the epigenetic alterations caused by the tungsten-alloy exposure of $\mathrm{C} 2 \mathrm{C} 12$ cultures (with higher than $90 \%$ cell viability after exposure to $1000 \mu \mathrm{M}$ metal solution) highlight the potential role of tungsten-alloy in mediating different epigenetic modifications independent of the involvement of dead cells. $\mathrm{C} 2 \mathrm{C} 12$ thus appeared to be particularly prone to histone modifications triggered by short term tungsten-alloy exposure with minimal impact on cell viability. We did not detect any effect of nickel on H3-Ser10 phosphorylation as opposed to the previous study that reported nickel mediated increased H3-Ser10 phosphorylation in human lung carcinoma A549 cultures (Ke et al., 2008). Also, methylation levels at trimethyl-H3-Lys4 appeared to be unaffected in all our culture systems even at high concentrations of cobalt in contrast to increased methylation of H3-Lys4 reported in A549 cells (Li, xet al., 2009). This may be due to the differential sensitivity of cells and/or diverse metal solutions used in our study.

We report here dephosphorylation of H3-Ser10 and hypoacetylation of H3 caused by tungsten-alloy but not tungsten in $\mathrm{C} 2 \mathrm{C} 12$ and hippocampal primary neuronal cultures, which highlights the synergistic epigenetic effects of tungsten along with nickel and cobalt that parallels and/or contributes to synergistic genotoxic effects of tungsten-alloy reported by previous studies (Lombaert et al., 2004, 2008; Van Goethem et al., 1997). These synergistic epigenetic effects are further corroborated by statistically significant reduction of $\mathrm{H3}$ -
Ser10 phosphorylation caused by tungsten-alloy as compared to cobalt concentration ( $\mathrm{CoA}$ ) equivalent to the percentage that was used in the preparation of tungsten-alloy in $\mathrm{C} 2 \mathrm{C} 12$ cells. When cobalt and tungsten carbide particles are in close contact, the generation of reactive oxygen species may take place, disturbing signaling pathways involved in proliferation, apoptosis, transformation, and senescence (Lison et al., 1995; Lu, et al., 2005). Tungsten carbide-cobalt mixture has been shown to trigger DNA fragmentation and rearrangements of nucleosome/chromatin assembly in human peripheral blood mononucleated cells thus contributing to apoptosis (Lombaert et al., 2004, 2008). Epidemiological studies have also identified an increased risk of lung cancer among workers exposed to hard metal dusts comprising tungsten carbide-cobalt mixture (Lasfargues et al., 1994) further suggesting their synergistic genotoxic and/or carcinogenic potentials.

Calcium is a potential cellular contributor that can interfere with and/or mediate heavy metal mediated histone modifications (Huang et al., 2005). It has been previously reported that heavy metal ions can affect calcium mobilization by stimulating the release of intracellular calcium stores, thereby increasing free intracellular calcium levels (McNulty and Taylor, 1999; Miledi, et al., 1989; Smith, et al., 1989). These alterations in intracellular calcium may be caused by complex interactions of heavy metal ions with cell-surface receptors and/or voltage-gated calcium channels or with different intracellular targets (McNulty and Taylor, 1999; Miledi, et al., 1989; Platt and Busselberg, 1994; Smith, et al., 1989). In order to shed a new light on the role of calcium in epigenetic modifications caused by tungsten-alloy, we 
A

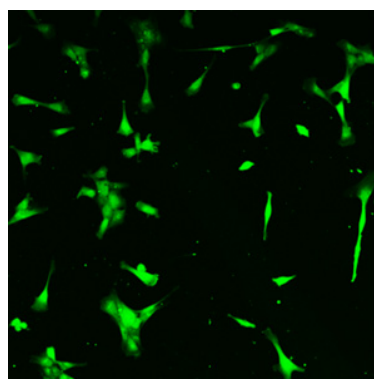

WA

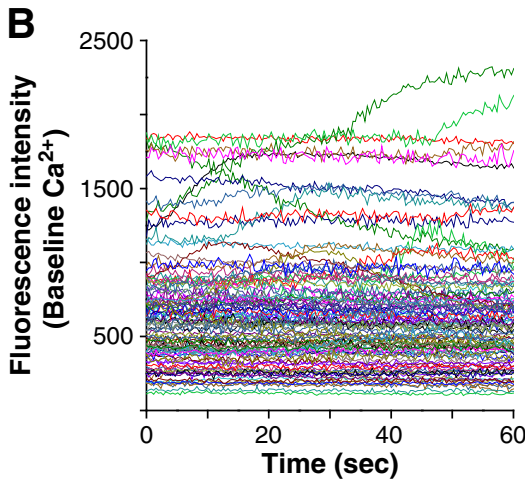

C
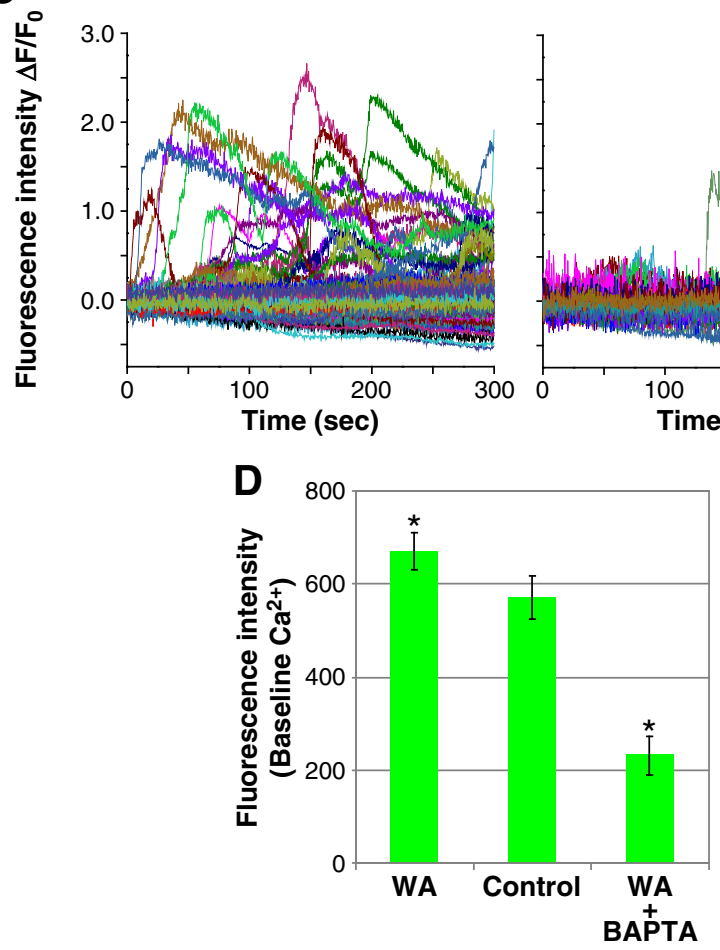

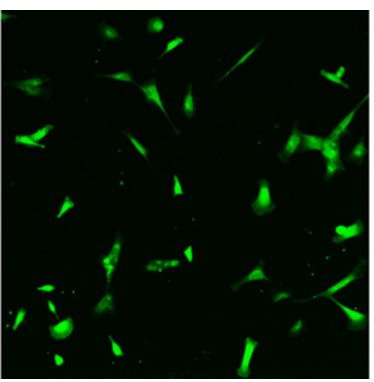

Control
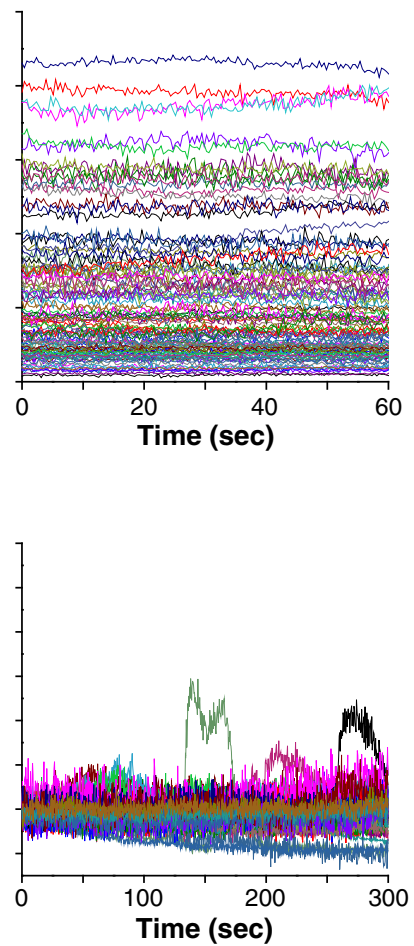

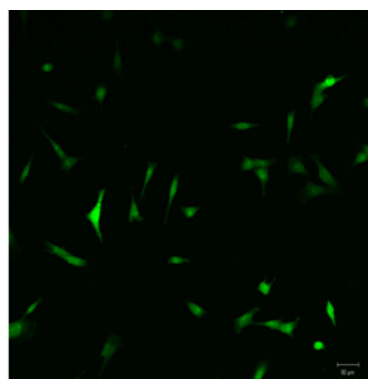

WA+BAPTA
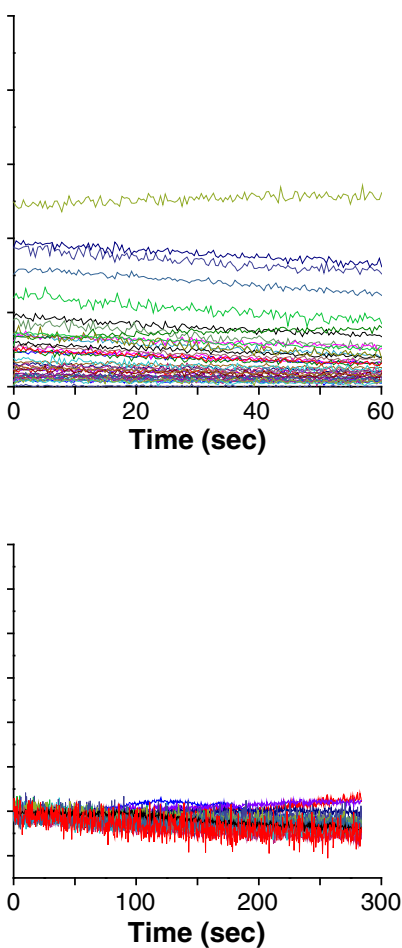

$\mathbf{E}_{100}$

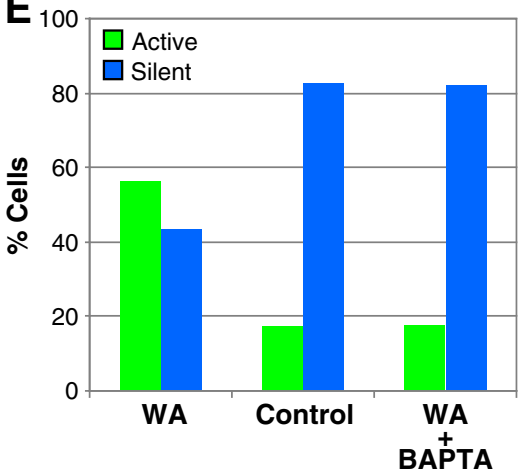

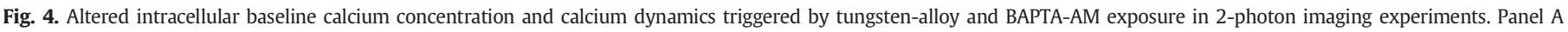

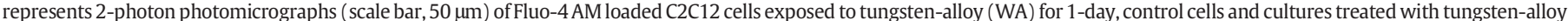

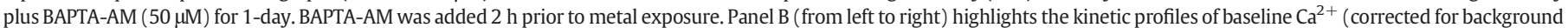

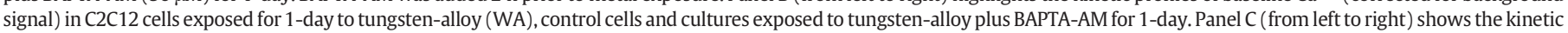

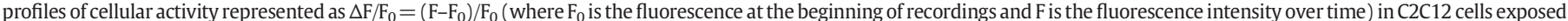

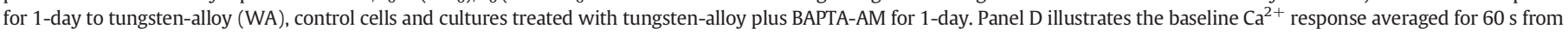

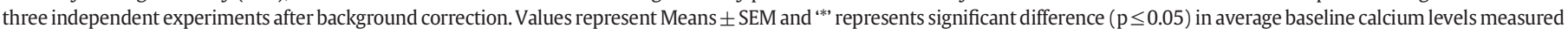

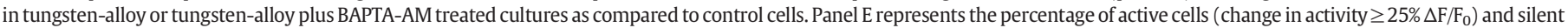
cells (change in activity $\leq 25 \% \Delta \mathrm{F} / \mathrm{F}_{0}$ ) after correction for a background signal from three independent experiments.

exposed cobalt and tungsten-alloy treated and control C2C12 cultures to different L-type calcium channel blockers and calcium chelators. The results showed that neither tungsten-alloy nor cobalt induced histone modifications were affected by calcium channel blockers (Fig. 3A). Similarly, no alteration in metal-induced $\mathrm{H} 3$ hypoacetylation was observed after co-treatment with calcium chelators (Fig. 3B). However, 
significant reversal of tungsten-alloy and cobalt induced H3-Ser10 dephosphorylation was observed with BAPTA-AM, resulting in phosphorylation levels similar to control conditions (Fig. 3B). Interestingly, C2C12 cultures exposed to tungsten-alloy or EGTA showed dramatic H3-Ser10 dephosphorylation, with BAPTA-AM pretreatment completely reversing this effect. This reduction of the H3-Ser10 phosphorylation level due to tungsten-alloy or EGTA exposure was possibly regulated by: (a) a small increase in the intracellular calcium released from intracellular stores (Fig. 4), and/or (b) a much stronger effect on calcium dynamics (Fig. 4). The reversal of H3-Ser10 dephosphorylation might be caused by competitive chelation of intracellular calcium by BAPTA-AM and/or silencing of intracellular calcium activity (Fig. 4). This implicates intracellular calcium homeostasis as an important element in the downstream signaling cascade triggered by tungsten-alloy or cobalt that induces H3-Ser10 dephosphorylation (Huang, et al., 2005). In fact, this H3-Ser10 dephosphorylation cascade may involve protein phosphatase PP2A in complex with calcium-sensitive protein kinase C, and/ or nuclear kinases targeting histone H3 (Huang, et al., 2005), which we plan to address in future studies.

In summary, the present study for the first time documented toxic and epigenetic effects in response to metal exposure in four diverse in vitro cell culture models. In particular, we found enhanced cytotoxic and altered epigenetic modifications in primary neuronal culture following long-term exposure to tungsten-alloy. Moreover, the transformations of histone modifications instigated in response to tungsten-alloy and not tungsten suggest that synergistic epigenetic effects of tungsten, nickel and cobalt may underlie the pathological effects of tungsten-alloy metals in neuronal and non-neuronal tissues. The reversal of histone modifications caused by heavy metals in response to calcium chelators highlights the importance of intracellular calcium and its dynamics in the pathological effects of tungsten-alloy and/or its alloy components. Taking into account the critical role of epigenetic modifications in regulating gene transcription, any possible alterations in histone modifications may thus affect downstream signaling cascades crucial for cell growth, differentiation, apoptosis, learning and memory mechanisms. More detailed studies are warranted to identify genespecific chromatin modifications to unravel the unique signaling pathways disrupted in response to heavy metal exposure and their nuclear mediators.

\section{Funding information}

This work was supported by grants from the Blast Spinal Cord Injury Research Program [HU0001-07-2-0008], Defense Medical Research and Development Program [NC706Z, NC706U] (ZG \& RV), Center for Neuroscience \& Regenerative Medicine Program [G17030] (ZG, RV and MKJ), AIRC MFAG 5386 (GC) and Marie Curie IRG (GC). Study sponsors had no involvement in the study design; collection, analysis and interpretation of data; the writing of the manuscript; the decision to submit the manuscript for publication.

Supplementary materials related to this article can be found online at doi:10.1016/j.taap.2011.04.002.

\section{Acknowledgments}

The work presented here was supported in part by grants from Blast Spinal Cord Injury Research Program [HU0001-07-2-0008], Defense Medical Research and Development Program [NC706Z, NC706U], and Center for Neuroscience \& Regenerative Medicine Program [G17030], AIRC MFAG 5386 and Marie Curie IRG. This manuscript does not represent US government views.

\section{References}

Akita, K., Okamura, H., Yoshida, K., Morimoto, H., Ogawa-Iyehara, H., Haneji, T., 2007. Cobalt chloride induces apoptosis and zinc chloride suppresses cobalt-induced apoptosis by Bcl-2 expression in human submandibular gland HSG cells. Int. J. Oncol. 31, 923-929.

Annunziato, A.T., Hansen, J.C., 2000. Role of histone acetylation in the assembly and modulation of chromatin structures. Gene Expr. 9, 37-61.

Bearden, L.J., Cooke, F.W., 1980. Growth inhibition of cultured fibroblasts by cobalt and nickel. J. Biomed. Mater. Res. 14, 289-309.

Bergmann, F., Keller, B.U., 2004. Impact of mitochondrial inhibition on excitability and cytosolic Ca2 + levels in brainstem motoneurones from mouse. J. Physiol. 555, 45-59.

Best, T.K., Siarey, R.J., Galdzicki, Z., 2007. Ts65Dn, a mouse model of Down syndrome, exhibits increased GABAB-induced potassium current. J. Neurophysiol. 97, 892-900.

Beyersmann, D., Hartwig, A., 2008. Carcinogenic metal compounds: recent insight into molecular and cellular mechanisms. Arch. Toxicol. 82, 493-512.

Cerutti, H., Casas-Mollano, J.A., 2009. Histone H3 phosphorylation: universal code or lineage specific dialects? Epigenetics 4, 71-75.

Chen, W., Hnizdo, E., Chen, J.Q., Attfield, M.D., Gao, P., Hearl, F., Lu, J., Wallace, W.E., 2005. Risk of silicosis in cohorts of Chinese tin and tungsten miners, and pottery workers (I): an epidemiological study. Am. J. Ind. Med. 48, 1-9.

Cheung, P., Allis, C.D., Sassone-Corsi, P., 2000. Signaling to chromatin through histone modifications. Cell 103, 263-271.

Clausen, J.L., Korte, N., 2009. Environmental fate of tungsten from military use. Sci. Total Environ. 407, 2887-2893.

Clayton, A.L., Mahadevan, L.C., 2003. MAP kinase-mediated phosphoacetylation of histone $\mathrm{H} 3$ and inducible gene regulation. FEBS Lett. 546, 51-58.

Costa, M., Davidson, T.L., Chen, H., Ke, Q., Zhang, P., Yan, Y., Huang, C., Kluz, T., 2005 Nickel carcinogenesis: epigenetics and hypoxia signaling. Mutat. Res. 592, 79-88.

Denkhaus, E., Salnikow, K., 2002. Nickel essentiality, toxicity, and carcinogenicity. Crit Rev. Oncol. Hematol. 42, 35-56.

Ellen, T.P., Kluz, T., Harder, M.E., Xiong, J., Costa, M., 2009. Heterochromatinization as a potential mechanism of nickel-induced carcinogenesis. Biochemistry 48, 4626-4632.

Florea, A.M., Busselberg, D., 2006. Occurrence, use and potential toxic effects of metals and metal compounds. Biometals 19, 419-427.

Hasan, M., Ali, S., Anwar, J., 1980. Cobalt-induced depletion of dopamine, norepinephrine \& 5-hydroxytryptamine concentration in different regions of the rat brain. Indian J. Exp. Biol. 18, 1051-1053.

He, H., Lehming, N., 2003. Global effects of histone modifications. Brief. Funct. Genomic Proteomic. 2, 234-243.

Hediger, M., Milburn, R.M., 1982. Adenosine triphosphate (ATP) hydrolysis promoted by cobalt (III). Participation of polynuclear metal complexes. J. Inorg. Biochem. 16, $165-182$.

Hinkle, P.M., Kinsella, P.A., Osterhoudt, K.C., 1987. Cadmium uptake and toxicity via voltage-sensitive calcium channels. J. Biol. Chem. 262, 16333-16337.

Hopp, M., Rogaschewski, S., Groth, T., 2003. Testing the cytotoxicity of metal alloys used as magnetic prosthetic devices. J. Mater. Sci. Mater. Med. 14, 335-345.

Huang, W., Batra, S., Atkins, B.A., Mishra, V., Mehta, K.D., 2005. Increases in intracellular calcium dephosphorylate histone $\mathrm{H} 3$ at serine 10 in human hepatoma cells: potential role of protein phosphatase $2 \mathrm{~A}$-protein kinase Cbetall complex. J. Cell Physiol. 205, 37-46.

Jaiswal, M.K., Keller, B.U., 2009. Cu/Zn superoxide dismutase typical for familial amyotrophic lateral sclerosis increases the vulnerability of mitochondria and perturbs Ca2 + homeostasis in SOD1G93A mice. Mol. Pharmacol. 75, 478-489.

Johnson, A.B., Barton, M.C., 2007. Hypoxia-induced and stress-specific changes in chromatin structure and function. Mutat. Res. 618, 149-162.

Johnson, D.R., Ang, C., Bednar, A.J., Inouye, L.S., 2010. Tungsten effects on phosphatedependent biochemical pathways are species and liver cell line dependent. Toxicol. Sci. 116, 523-532

Johnston, H.B., Thomas, S.M., Atterwill, C.K., 1993. Aluminium and iron induced metabolic changes in neuroblastoma cell lines and rat primary neural cultures. Toxicol In Vitro 7, 229-233.

Jordan, C., Whitman, R.D., Harbut, M., Tanner, B., 1990. Memory deficits in workers suffering from hard metal disease. Toxicol. Lett. 54, 241-243.

Kalinich, J.F., Emond, C.A., Dalton, T.K., Mog, S.R., Coleman, G.D., Kordell, J.E., Miller, A.C. McClain, D.E., 2005. Embedded weapons-grade tungsten alloy shrapnel rapidly induces metastatic high-grade rhabdomyosarcomas in F344 rats. Environ. Health Perspect. 113, 729-734.

Kane, M.A., Kasper, C.E., Kalinich, J.F., 2009. The use of established skeletal muscle cell lines to assess potential toxicity from embedded metal fragments. Toxicol. In Vitro 23, 356-359.

Ke, Q., Davidson, T., Chen, H., Kluz, T., Costa, M., 2006. Alterations of histone modifications and transgene silencing by nickel chloride. Carcinogenesis 27, 1481-1488.

Ke, Q., Li, Q., Ellen, T.P., Sun, H., Costa, M., 2008. Nickel compounds induce phosphorylation of histone $\mathrm{H} 3$ at serine 10 by activating JNK-MAPK pathway Carcinogenesis 29, 1276-1281.

Klein, R.C., Siarey, R.J., Caruso, A., Rapoport, S.I., Castellino, F.J., Galdzicki, Z., 2001. Increased expression of NR2A subunit does not alter NMDA-evoked responses in cultured fetal trisomy 16 mouse hippocampal neurons. J. Neurochem. 76, 1663-1669.

Lagarde, F., Leroy, M., 2002. Metabolism and toxicity of tungsten in humans and animals. Met. Ions Biol. Syst. 39, 741-759.

Lasfargues, G., Wild, P., Moulin, J.J., Hammon, B., Rosmorduc, B., Rondeau du Noyer, C. Lavandier, M., Moline, J., 1994. Lung cancer mortality in a French cohort of hardmetal workers. Am. J. Ind. Med. 26, 585-595.

Leonard, A., Lauwerys, R., 1990. Mutagenicity, carcinogenicity and teratogenicity of cobalt metal and cobalt compounds. Mutat. Res. 239, 17-27.

Li, Q., Ke, Q., Costa, M., 2009. Alterations of histone modifications by cobalt compounds. Carcinogenesis 30, 1243-1251. 
Linder, M.C., Hazegh-Azam, M., 1996. Copper biochemistry and molecular biology. Am. J. Clin. Nutr. 63, 797S-811S

Lison, D., Carbonnelle, P., Mollo, L., Lauwerys, R., Fubini, B., 1995. Physicochemica mechanism of the interaction between cobalt metal and carbide particles to generate toxic activated oxygen species. Chem. Res. Toxicol. 8, 600-606.

Lombaert, N., De Boeck, M., Decordier, I., Cundari, E., Lison, D., Kirsch-Volders, M., 2004. Evaluation of the apoptogenic potential of hard metal dust (WC-Co), tungsten carbide and metallic cobalt. Toxicol. Lett. 154, 23-34.

Lombaert, N., Lison, D., Van Hummelen, P., Kirsch-Volders, M., 2008. In vitro expression of hard metal dust (WC-Co)-responsive genes in human peripheral blood mononucleated cells. Toxicol. Appl. Pharmacol. 227, 299-312.

Lu, H., Shi, X., Costa, M., Huang, C., 2005. Carcinogenic effect of nickel compounds. Mol. Cell. Biochem. 279, 45-67.

M'Bemba-Meka, P., Lemieux, N., Chakrabarti, S.K., 2005. Role of oxidative stress, mitochondrial membrane potential, and calcium homeostasis in nickel sulfateinduced human lymphocyte death in vitro. Chem. Biol. Interact. 156, 69-80.

Marquet, P., Francois, B., Vignon, P., Lachatre, G., 1996. A soldier who had seizures after drinking quarter of a litre of wine. Lancet 348, 1070.

McInturf, S.M., Bekkedal, M.Y., Wilfong, E., Arfsten, D., Gunasekar, P.G., Chapman, G.D., 2008. Neurobehavioral effects of sodium tungstate exposure on rats and their progeny. Neurotoxicol. Teratol. 30, 455-461.

McNulty, T.J., Taylor, C.W., 1999. Extracellular heavy-metal ions stimulate Ca2+ mobilization in hepatocytes. Biochem. J. 339 (Pt. 3), 555-561.

Miledi, R., Parker, I., Woodward, R.M., 1989. Membrane currents elicited by divalent cations in Xenopus oocytes. J. Physiol. 417, 173-195.

Miller, A.C., Mog, S., McKinney, L., Luo, L., Allen, J., Xu, J., Page, N., 2001. Neoplastic transformation of human osteoblast cells to the tumorigenic phenotype by heavy metal-tungsten alloy particles: induction of genotoxic effects. Carcinogenesis 22 $115-125$.

Moggs, J.G., Orphanides, G., 2004. The role of chromatin in molecular mechanisms of toxicity. Toxicol. Sci. 80, 218-224.

Perez-Cadahia, B., Drobic, B., Davie, J.R., 2009. H3 phosphorylation: dual role in mitosis and interphase. Biochem. Cell Biol. 87, 695-709.

Peuster, M., Fink, C., von Schnakenburg, C., 2003. Biocompatibility of corroding tungsten coils: in vitro assessment of degradation kinetics and cytotoxicity on human cells. Biomaterials 24, 4057-4061.

Platt, B., Busselberg, D., 1994. Combined actions of $\mathrm{Pb} 2+, \mathrm{Zn} 2+$, and $\mathrm{Al} 3+$ on voltageactivated calcium channel currents. Cell. Mol. Neurobiol. 14, 831-840.

Riley, M.R., Boesewetter, D.E., Turner, R.A., Kim, A.M., Collier, J.M., Hamilton, A., 2005 Comparison of the sensitivity of three lung derived cell lines to metals from combustion derived particulate matter. Toxicol. In Vitro 19, 411-419.

Rubin, C.S., Holmes, A.K., Belson, M.G., Jones, R.L., Flanders, W.D., Kieszak, S.M., Osterloh, J., Luber, G.E., Blount, B.C., Barr, D.B., Steinberg, K.K., Satten, G.A., McGeehin, M.A. Todd, R.L., 2007. Investigating childhood leukemia in Churchill County, Nevada. Environ. Health Perspect. 115, 151-157.
Santos-Rosa, H., Schneider, R., Bannister, A.J., Sherriff, J., Bernstein, B.E., Emre, N.C., Schreiber, S.L., Mellor, J., Kouzarides, T., 2002. Active genes are tri-methylated at K4 of histone H3. Nature 419, 407-411.

Schmalz, G., Garhammer, P., 2002. Biological interactions of dental cast alloys with oral tissues. Dent. Mater. 18, 396-406.

Shechter, D., Dormann, H.L., Allis, C.D., Hake, S.B., 2007. Extraction, purification and analysis of histones. Nat. Protoc. 2, 1445-1457.

Sheppard, P.R., Speakman, R.J., Ridenour, G., Witten, M.L., 2007. Temporal variability of tungsten and cobalt in Fallon. Nevada. Environ. Health Perspect. 115, 715-719.

Sirover, M.A., Loeb, L.A., 1976. Infidelity of DNA synthesis in vitro: screening for potential metal mutagens or carcinogens. Science 194, 1434-1436.

Smith, J.B., Dwyer, S.D., Smith, L., 1989. Cadmium evokes inositol polyphosphate formation and calcium mobilization. Evidence for a cell surface receptor that cadmium stimulates and zinc antagonizes. J. Biol. Chem. 264, 7115-7118.

Steinmaus, C., Lu, M., Todd, R.L., Smith, A.H., 2004. Probability estimates for the unique childhood leukemia cluster in Fallon, Nevada, and risks near other U.S. Military aviation facilities. Environ. Health Perspect. 112, 766-771.

Stoll, J., Galdzicki, Z., 1996. Reduced expression of voltage-gated sodium channels in neurons cultured from trisomy 16 mouse hippocampus. Int. J. Dev. Neurosci. 14, 749-760.

Thomas, V.G., Roberts, M.J., Harrison, P.T., 2009. Assessment of the environmental toxicity and carcinogenicity of tungsten-based shot. Ecotoxicol. Environ. Saf. 72, 1031-1037.

Thompson, C.M., Markesbery, W.R., Ehmann, W.D., Mao, Y.X., Vance, D.E., 1988. Regional brain trace-element studies in Alzheimer's disease. Neurotoxicology 9, 1-7.

Tsaousi, A., Jones, E., Case, C.P., 2010. The in vitro genotoxicity of orthopaedic ceramic (Al203) and metal (CoCr alloy) particles. Mutat. Res. 697, 1-9.

Valko, M., Morris, H., Cronin, M.T., 2005. Metals, toxicity and oxidative stress. Curr. Med. Chem. 12, 1161-1208.

van der Voet, G.B., Todorov, T.I., Centeno, J.A., Jonas, W., Ives, J., Mullick, F.G., 2007. Metals and health: a clinical toxicological perspective on tungsten and review of the literature. Mil. Med. 172, 1002-1005.

Van Goethem, F., Lison, D., Kirsch-Volders, M., 1997. Comparative evaluation of the in vitro micronucleus test and the alkaline single cell gel electrophoresis assay for the detection of DNA damaging agents: genotoxic effects of cobalt powder, tungsten carbide and cobalt-tungsten carbide. Mutat. Res. 392, 31-43.

Ziech, D., Franco, R., Pappa, A., Malamou-Mitsi, V., Georgakila, S., Georgakilas, A.G., Panayiotidis, M.I., 2010. The role of epigenetics in environmental and occupational carcinogenesis. Chem. Biol. Interact. 188, 340-349.

Zippo, A., Serafini, R., Rocchigiani, M., Pennacchini, S., Krepelova, A., Oliviero, S., 2009. Histone crosstalk between H3S10ph and H4K16ac generates a histone code that mediates transcription elongation. Cell 138, 1122-1136.

Zou, W., Zeng, J., Zhuo, M., Xu, W., Sun, L., Wang, J., Liu, X., 2002. Involvement of caspase-3 and p38 mitogen-activated protein kinase in cobalt chloride-induced apoptosis in PC12 cells. J. Neurosci. Res. 67, 837-843. 